\title{
A FORMAÇÃO INICIAL DOS PROFESSORES, A PEDAGOGIA E A DIDÁTICA EM UMA PERSPECTIVA DIALÓGICA ${ }^{1}$
}

\author{
LA FORMACIÓN INICIAL DE LOS PROFESORES, LA PEDAGOGÍA Y LA \\ DIDÁCTICA EN UNA PERSPECTIVA DIALÓGICA
}

\author{
INITIAL TEACHERS' TRAINING, PEDAGOGY AND DIDACTICS IN A \\ DIALOGICAL PERSPECTIVE
}

\author{
Cloves Santos de MORAES ${ }^{2}$ \\ Cícera Janaína Rodrigues LIMA ${ }^{3}$ \\ Célia de Jesus Silva MAGALHÃES ${ }^{4}$
}

RESUMO: Este ensaio problematiza a articulação que deve existir entre a formação inicial dos professores, a pedagogia e a didática, pois a pedagogia busca fundamentar as práticas docentes, os saberes pedagógicos que, como desdobramento, darão sentido à ação docente. As ideias aqui expostas pautam-se em pesquisas e ensaios que abordam a referida temática. Concluímos que importância dos saberes do campo pedagógico na formação docente, dentre eles os cursos de licenciatura, devem contribuir disponibilizando aos professores uma formação interligada aos conhecimentos desse campo, já que são de suma importância para o desenvolvimento profissional dos professores.

PALAVRAS-CHAVE: Formação inicial docente. Pedagogia. Didática.

RESUMEN: Este ensayo problematiza la articulación que debe existir entre la formación inicial de los profesores, la pedagogía y la didáctica, ya que la pedagogía busca fundamentar las prácticas docentes, los saberes pedagógicos que, como desdoblamiento, darán sentido a la acción docente. Las ideas aquí expuestas se basan en investigaciones y ensayos que abordan la referida temática. Concluimos que la importancia de los saberes del campo pedagógico en la formación docente, entre ellos los cursos de licenciatura, deben contribuir aportando a los profesores una formación

\footnotetext{
${ }^{1}$ Este texto consiste em uma versão ampliada e atualizada, em julho de 2017, do trabalho originalmente intitulado de "Tecendo relações entre a pedagogia e a formação docente. Publicado com a participação do Prof. Me. Osmar Hélio Alves Araújo nos Anais do $10^{\circ}$ Encontro Internacional de Formação de Professores $/ 11^{\circ}$ Fórum Permanente Internacional de Inovação Educacional, realizados na Universidade Tiradentes - Aracaju-SE, entre 15 - 19 de Maio 2017. Disponível em: < https://eventos.set.edu.br/index.php/enfope/article/view/4559 >.

${ }^{2}$ Graduando em Letras pela Universidade Regional do Cariri (URCA) - VII semestre. Tem experiência como professor na educação básica. Atualmente, é bolsista PIBIC/URCA/FUNCAP. E-mail: clovessantos0@gmail.com

${ }^{3}$ Graduada em Letras pela Universidade Regional do Cariri (URCA). Especialista em Língua Portuguesa e Literatura Africana pela Universidade Regional do Cariri (URCA). Atualmente, é professora da rede básica e do ensino superior. E-mail: janainarodrigueslima@live.com

${ }^{4}$ Graduação em História pela Universidade Regional do Cariri (1986) e Mestrado em Educação pela Universidade Federal da Paraíba (2011). Atualmente é professora substituta da Universidade Regional do Cariri e diretora acadêmica - Unidade Missão Velha da Universidade Regional do Cariri. E-mail: celia.magalhaes@urca.br
} 
interconectada a los conocimientos de ese campo, ya que son de suma importancia para el desarrollo profesional de los profesores.

PALABRAS-CLAVE: Formación inicial de los profesores. Pedagogía. Didáctica.

ABSTRACT: This essay problematizes the articulation that must exist between the initial training of teachers, the Pedagogy and Didactics, since the Pedagogy seeks to give foundation to teaching practices, the pedagogical knowledge that, as results, will give meaning to the teaching action. The ideas presented here are based on researches and essays that deal with this theme. We conclude that the importance of the knowledge of the pedagogical field in the teacher training, among them the undergraduate teaching courses, should contribute making available to the teachers a formation linked to the knowledge of this field, since they are of paramount importance for the professional development of the teachers.

KEYWORDS: Initial teachers' training. Pedagogy. Didactics.

\section{Considerações iniciais}

A formação inicial dos professores deve ocorrer de modo a fomentar a construção do conhecimento, assim como a instigar os futuros docentes a desenvolverem uma prática pedagógica em uma perspectiva crítico-reflexiva. Conforme postulam Araújo, Rodrigues, Aragão (2017), Araújo e Ribeiro (2016), Libâneo (2002, 2006), Franco (2008, 2012, 2015), Candau (2008) Franco e Gilberto (2011), Franco, Libâneo e Pimenta (2011), os professores necessitam dos conhecimentos do campo da pedagogia e da didática, visto que a pedagogia, enquanto ciência da educação, estuda o fenômeno educativo e busca fundamentar as práticas docentes, os saberes pedagógicos que, como desdobramento, darão sentido à ação docente.

A pedagogia, enquanto ciência que busca compreender o fenômeno educativo, auxilia o professor a desenvolver uma prática pedagógica crítica e reflexiva, bem como contribui para a construção/reconstrução dessa mesma prática em uma perspectiva de práxis. A pedagogia e, por consequência, a didática, nesse sentido, contribuem para a fundamentação das práticas docentes e para a construção dos saberes pedagógicos, bem como para atribuir intencionalidades político-pedagógicas às práticas docentes.

Dessa forma, refletir sobre a formação inicial dos professores, a pedagogia e a didática em uma perspectiva dialógica é compreender, a priori, que esses são campos indivisíveis. Quando se trata da necessária relação entre a formação inicial dos 
professores, a pedagogia e a didática, Araújo, Rodrigues, Aragão (2017, p. 03) sinalizam que "uma formação docente articulada à pedagogia e à didática contribui para a formação de um professor que constrói e reconstrói a sua prática por meio da reflexão crítica de pensar a prática a partir da própria prática em suas múltiplas nuances".

Considerando o exposto, a formação docente, seja ela inicial ou contínua e das diversas áreas do conhecimento, deve ser desenvolvida de modo coadunado à pedagogia e a didática. Logo, este ensaio traz para o debate essa necessária relação entre a formação docente, a pedagogia e a didática, pois estas últimas devem ocupar lugar de destaque na formação dos professores. Uma atuação docente desvinculada destes campos limita o fenômeno educativo, inibe a construção dos saberes docentes pedagógicos, impede que o professor se desenvolva como intelectual (ARAÚJO; RODRIGUES; ARAGÃO, 2017).

Cumpre ainda destacarmos, a título introdutório, que a valoração da pedagogia e da didática na formação inicial dos professores auxiliará os mesmos a compreenderem as especificidades do processo educativo, assim como para a formação de um professor capaz de construir saberes, entre eles, os saberes pedagógicos.

\section{A formação docente e a pedagogia}

Pensar sobre as possibilidades que têm a Pedagogia e a Didática de colaborarem para a construção de espaços pedagógicos prazerosos, criativos e interativos para cativar os discentes é ao mesmo tempo buscar subsídios para tornar a escola um lugar de construção do conhecimento partilhado entre docentes e discentes. Entretanto, o professor necessita de uma formação pedagógica que lhe torne um sujeito capaz de dialogar com as circunstâncias postas pela prática docente. Uma formação pedagógica que o permita construir práticas conforme as reais necessidades dos discentes e, desse modo, envolvê-los nos processos de ensino e aprendizagem, é necessária. Nesta perspectiva, compreendemos que a formação docente deve levar os professores a serem sujeitos capazes de mobilizar os alunos para a construção do conhecimento a partir de uma educação problematizadora, democrática e equânime. Nessa perspectiva, Franco (2012) assinala que:

Cabe pensar também que a formação de professores não se efetua no vazio, mas deve estar vinculada a uma intencionalidade, a uma 
política, a uma epistemologia, a pesquisas aprofundadas dos saberes pedagógicos. A formação de professores desvinculada de um projeto político só pode caracterizar uma concepção extremamente pragmatista, reprodutivista, tecnicista da ação docente (FRANCO, 2012, p. 167).

Os professores carecem de uma formação crítica, dialógica e reflexiva que os permita desenvolver práticas pedagógicas que supram as necessidades dos alunos, os quais, na sua grande maioria, são carentes de uma educação pública de qualidade. No entanto, ressaltamos aqui a importância da participação e envolvimento dos discentes no processo de ensino para que, de fato, a aprendizagem ocorra, visto que a construção do conhecimento exige o envolvimento ativo dos mesmos. Disso decorre a importância do professor possuir uma formação fincada na Pedagogia, sendo capaz de construir práticas pedagógicas que ajudem os alunos a desenvolverem suas capacidades cognitivas, reflexivas e intelectuais, pois a escola, enquanto contexto formativo, deve proporcionar ao seu corpo discente uma educação ética, crítica, problematizadora, responsável, e, conforme postulou Nóvoa (2009), que os ajudem a ultrapassarem as fronteiras que tantas vezes lhe são traçadas como destino pelo nascimento, pela família ou pela sociedade.

Em face do exposto, cabe reiterar que a formação pedagógica dos professores emerge como uma necessidade da população docente que urge ser sanada no cenário educacional, pois os professores precisam, por meio de suas práticas pedagógicas, atrair os discentes e mantê-los na escola a fim de cumprirem o seu trabalho que é ensinar. Entrento, Lessard e Tardif (2005) salientam que:

Os alunos são clientes forçados, obrigados que são a ir para a escola. A centralidade da disciplina e da ordem no trabalho docente, bem como a necessidade quase constante de "motivar" os alunos, mostram que os professores se confrontam com o problema da participação do seu objeto de trabalho - os alunos - no trabalho de ensino e aprendizagem. Eles precisam convencer os alunos que "a escola é boa para eles", ou imprimir às suas atividades uma ordem tal que os recalcitrantes não atrapalhem o desenvolvimento normal das rotinas do trabalho (LESSARD e TARDIF, 2005, p.35).

Seguindo a linha de pensamento dos autores e considerando que muitos professores apresentam dificuldades em saber organizar uma aula pedagogicamente, criando um espaço propício para que a aprendizagem ocorra, ressalta-se aqui que caberá 
à Didática lhes fornecer os instrumentos teóricos e práticos para a construção de aulas dinâmicas e interativas, capazes de atrair os alunos para a escola, pois se os mesmos não se evolverem no processo de ensino, por consequência, a aprendizagem não se efetivará. Entretanto, os alunos, na sua grande maioria, são carentes de um processo de ensino que os envolva como sujeitos ativos e construtores do conhecimento. Essa carência poderá ser suprida à medida em que houver uma melhor qualificação dos professores, ou seja, uma formação docente que se paute, sobretudo, no campo pedagógico e instigue os professores a buscarem novos caminhos didático-pedagógicos visando a melhoria dos processos de ensino e aprendizagem.

Compreende-se, ainda, que os professores devem construir práticas pedagógicas interligadas ao contexto contemporâneo perpassado pelas novas tecnologias. Cada vez mais os alunos precisam estar inseridos em ambientes de aprendizagem que disponibilizem recursos tecnológicos e os possibilitem construir e reconstruir o conhecimento de modo crítico e reflexivo. Dessa maneira, faz-se necessário professores bem preparados, possuidores dos conhecimentos específicos da sua área de formação, assim como construtores de saberes pedagógicos, para que, dessa forma, o professor seja capaz de materializar um ensino intencional que busca, em sua essência, formar alunos críticos em face da sociedade globalizada.

Franco $(2015$, p. 607) afirma que os saberes pedagógicos: "[...] permitem ao sujeito colocar-se em condição de dialogar com as circunstâncias dessa prática, dandolhe possibilidade de perceber e auscultar as contradições. Assim, ele pode articular teoria e prática". Entretanto, o que se observa no cenário educacional brasileiro são professores que, a partir das suas práticas, não conseguem construir esses saberes e, como consequência, não desenvolvem práticas pedagógicas que oportunizem aos discentes uma aprendizagem significativa. Isto se deve, em parte, pela precariedade da formação inicial dos professores que ainda ocorre deslocada da realidade das escolas brasileiras, às condições de trabalho que são oferecidas ao professor, quantidade de alunos por turmas, baixos salários, à falta dos materiais didático-pedagógicos e à valorização da escola como espaço de formação e consolidação de uma sociedade democrática e progressista, entre outros elementos. Diante do exposto, ressalta-se que as aulas construídas neste espaço de conflitos e tensões ante o cenário apresentado não terão direção e sentido para os discentes, os quais são, cada vez mais, carentes de uma educação crítica, responsável e progressista. 
Ressalta-se aqui que é responsabilidade da universidade possibilitar aos futuros professores a apreensão dos conhecimentos específicos da sua área de formação, porém não basta apenas esses conhecimentos específicos, faz-se necessário também os saberes pedagógicos. Nesse sentido, Franco (2015) nos adverte que:

\begin{abstract}
A grande dificuldade em relação à formação de professores é que, se quisermos ter bons professores, teremos de formá-los como sujeitos capazes de produzir conhecimentos, ações e saberes sobre a prática. Não basta fazer uma aula; é preciso saber porque tal aula se desenvolveu daquele jeito e naquelas condições: ou seja, é preciso a compreensão e leitura da práxis (FRANCO, 2015, p. 607).
\end{abstract}

Considerando as contribuições da autora, enfatiza-se aqui a necessidade do futuro professor apreender os conhecimentos específicos, a partir da sua formação inicial, e também os saberes do campo pedagógico, pois esses saberes o auxiliarão na construção e reconstrução das suas práticas, de modo crítico e reflexivo. Em relação à importância dos saberes didático-pedagógicos, Franco (2013, p. 152) afirma que: "A didática ainda fará a diferença quando se fizer presente na prática dos docentes na universidade. Até porque a didática, como teoria do ensino, preocupa-se com a finalidade do que se ensina e isso é fundamental para organizar a prática". Seguindo esse raciocínio, é possível agregar as contribuições de Libâneo (2010, p. 36), pois segundo esse autor: "O conhecimento provido pela didática é o que permite uma contínua reelaboração da experiência profissional, de modo que o professor possa pensar sobre sua ação".

Na mesma linha de raciocínio, Araújo e Magalhães (2016) tem discutido que a Didática e a Pedagogia levam o professor a refletir cada dia e sempre mais a partir da ação que empreende e colocar-se em processo de autoformação, assim como contribuem com os professores na reconstrução de suas práticas docentes. Entretanto, assinalam que a Didática e a Pedagogia não toleram a distância das práticas pedagógicas dos professores, pois a distância limita a construção de saberes didáticos-pedagógicos. Assumem os autores que:

[...] uma formação docente fincada na Didática e na Pedagogia permitirá ao professor construir e reconstruir sua prática, assim como descortinar caminhos rumo a uma experiência docente de êxodo, de passagem da repetição para a autonomia intelectual, do individualismo para o coletivo, do comodismo para a militância pedagógica, e assim o professor poderá fazer da sua própria prática pedagógica laboratório de formação (ARAÚJO E MAGALHÃES, 2016, p. 225). 
Desse modo, portanto, defende-se aqui uma formação docente, imbricada ao campo da Pedagogia e da Didática, que possibilite aos professores construírem saberes pedagógicos que os levem a serem mediadores de um ensino mais significativo e transformador do contexto social. Por isso, os professores precisam ser formados de modo dialógico, crítico e reflexivo para que se possa melhorar a qualidade da educação. Dessa forma, entendemos que o campo da Pedagogia poderá auxiliar os professores na responsabilidade que se constitui o ato de ensinar.

Diante da discussão já empreendida, sublinha-se que construir saberes pedagógicos significa construir conhecimentos referentes às intencionalidades que devem permear o ato de ensinar. São eles que conferem sentido e direção às aulas construídas no espaço escolar. Dessa forma, é oportuno salientar que a prática do professor só será prática pedagógica se estiver revestida dos sabres pedagógicos em sua constituição. A esse respeito, Franco (2015) assim se expressa:

Portanto, uma aula só se torna uma prática pedagógica quando ela se organiza em torno: de intencionalidades, de práticas que dão sentido às intencionalidades; de reflexão contínua para avaliar se a intencionalidade está atingindo todos; de acertos contínuos de rota e de meios para se atingir os fins propostos pelas intencionalidades. Configura-se sempre como uma ação consciente e participativa (FRANCO, 2015, p. 605).

Partindo do raciocínio da autora, entende-se que os saberes pedagógicos são construídos pelos próprios professores quando refletem e analisam suas práticas docentes em um movimento de fazer/refletir/transformar e, assim, transformá-las tendo em vista a melhoria da prática dos processos de ensino e aprendizagem. Araújo e Magalhães (2016) corroboram assinalando que:

[...] que não basta planejar e executar práticas e mais práticas, propalar intenções e mais intenções pedagógicas, tomar nota das necessidades gritantes dos alunos, se essas práticas não forem acompanhadas de uma ação efetiva de reflexão, que permita ao professor a leitura e a compreensão dos movimentos das suas práticas. Nesse passo, as práticas docentes ficam sem efeito real, se elas não forem acompanhadas dos movimentos da práxis, por parte de cada professor em particular, e de uma tomada de consciência mais viva, dinâmica e de uma ação efetiva de análise da realidade contemporânea, assim como das necessidades dos alunos que vivem nos condicionamentos dessa realidade (ARAÚJO E MAGALHÃES, 2016, p. 225). 
Pimenta e Lima (2009) apresentam uma importante assertiva sobre as contribuições da Pedagogia e da Didática para a atividade docente. Segundo as autoras:

\begin{abstract}
A Pedagogia - ciência prática da e para a práxis educacional, na medida em que possibilita uma autêntica análise crítica da cultura pedagógica facilitando ao professor debruçar-se sobre as dificuldades concretas que encontra em seu trabalho, bem como superá-las de maneira criadora, e a Didática, cujo cerne de estudos é a atividade docente de ensinar, constituem-se em instrumental importante para ampliação da unidade entre a teoria e a prática do trabalho dos professores e coordenadores envolvidos nos cursos de formação de professores (PIMENTA E LIMA, 2009, p. 196).
\end{abstract}

Dessa forma, faz-se necessário os professores contarem com uma formação fincada no campo pedagógico, como já sublinhado, haja vista que os referidos saberes permitirão ao docente a leitura e a análise de suas próprias práticas.

Os saberes pedagógicos, portanto, podem auxiliar os professores na construção de aulas capazes de despertar no aluno o senso crítico e mobilizá-los para a atividade intelectual. Faz-se necessário que a formação dos professores esteja entrelaçada pelos conhecimentos da Pedagogia, como ciência que tem por objeto de estudo o fenômeno educativo. Dessa forma, o professor, consciente da importância da sua aula para a formação dos alunos, necessita planejar suas práticas revestindo-as de intencionalidades políticas e transformadoras visando a aprendizagem dos discentes. No rastro do exposto, o professor deve estar consciente que uma ação pedagógica transformadora ocorre à medida que se pauta no diálogo com os sujeitos envolvidos, os quais, paulatinamente, devem se transformar. Para o desenvolvimento dessa prática pedagógica, entretanto, o professor deve saber planejá-la a partir de situações desafiadoras, intrigantes e transformadoras do meio social.

São muitos os desafios a serem superados visando tornar a prática docente atrativa e coerente com as gerações contemporâneas. Entretanto, atingir esses objetivos pode se mostrar laborioso. É nesse contexto que a Pedagogia se mostra útil aos professores, auxiliando na construção de uma prática pedagógica transformadora, pois uma das funções da Pedagogia é levar o professor a refletir sobre o que ensina. No entanto, muitos profissionais que hoje exercem a docência não receberam uma formação pedagógica producente, pois não foram estimulados a transformarem os conteúdos específicos em saberes pedagógicos, assim como os professores, na sua grande maioria, não compreendem os elementos que constituem os processos de ensino e aprendizagem. 
Franco (2015, p. 605) corrobora nossa afirmação explicando que a: "[...] prática docente, para se transformar em prática pedagógica, requer, pelo menos, dois movimentos: o da reflexão crítica de sua prática e o da consciência das intencionalidades que presidem suas práticas”. Araújo e Magalhães (2017), por sua vez, agregam que a formação docente não deve ser apenas uma preparação para a construção das práticas pedagógicas, mas a busca contínua da reinvenção do campo da Didática a partir do vivido no chão das escolas brasileiras. Logo, fica patente que a Pedagogia e a Didática poderão contribuir com os professores na construção de práticas pedagógicas transformadoras.

Nesta perspectiva, compreende-se que conhecer os conteúdos da sua área de formação é necessário. Conhecer a maneira de mediar o processo de ensino, entretanto, constitui-se em condição fundamental para que o processo de aprendizagem aconteça. Contudo, é perceptível que muitos professores não conseguiram ainda entender a importância da Pedagogia para a construção de novas práticas pedagógicas. Além disso, no Brasil, há resquícios da insuficiente formação didático-pedagógica nos cursos de licenciatura. O modelo de formação conservadora dos professores que se pautavam na tendência liberal tecnicista (LIBÂNEO, 2008), com ênfase em técnicas e métodos, validada pelas leis 5.540/68 e 5.692/71 do período da ditadura militar no Brasil (SAVIANI, 1991), a qual era supostamente boa porque se ancorava na conhecida fórmula " $3+1$ ", em que as disciplinas de cunho pedagógico justapunham-se às disciplinas de conteúdo (PEREIRA, 1999), parece ainda nortear os cursos de licenciatura.

A esse respeito, Franco (2013) assim se expressa:

[...] Didática para fundamentar as práticas de docentes no ensino superior é uma preocupação antiga, uma vez que esses docentes, em sua grande maioria, não se formaram professores, mas profissionais de diferentes áreas que, por serem especialistas em suas áreas de formação, tornam-se professores. Possuem os saberes da área, muitas vezes possuem os saberes produzidos pela experiência, mas, na maioria das vezes, não dispõem dos saberes didáticos ou pedagógicos (FRANCO, 2013, p.152).

A partir das contribuições da autora, conclui-se essa discussão asseverando a importância da formação dos professores ser construída coadjuvada pela Pedagogia que, conforme expressado, auxilia o professor na construção de suas práticas pedagógicas. Em linhas conclusivas, apoia-se aqui nas contribuições de Franco (2012, 
p. 168) ao assinalar que: "A Pedagogia e Didática têm pela frente o desafio de desvincular a escola de suas práticas ultrapassadas e oferecer espaços à construção coletiva de novas vivências, conhecimentos e saberes". Assim, diante da discussão empreendida, convém retomar que uma das possíveis maneiras de melhorar a educação no Brasil é investindo na formação docente, isto é, formando pedagogicamente os professores, com arrimo na Pedagogia e na Didática, para que, assim, os professores sejam capazes de atuarem no ambiente escolar e contribuírem para a melhoria da educação no país.

\section{Considerações finais}

Em acordo com as questões apresentadas e dada à importância dos saberes do campo pedagógico na formação docente, os cursos de licenciatura, entre outros espaços de formação docente, devem contribuir disponibilizando aos professores uma formação interligada aos conhecimentos do campo pedagógico, dada a necessidade latente desses conhecimentos. Deste modo, o professor em formação deve estar consciente da importância dos saberes pedagógicos para a construção de práticas transformadoras, pois, advoga-se aqui que a Pedagogia é um fator determinante para uma formação docente qualitativa.

Nesta perspectiva, a formação dos professores precisa interligar-se ao campo da Pedagogia, visto que a mesma poderá auxiliar os professores no entendimento da complexidade que se constitui o fenômeno educativo, isto é, os referidos saberes contribuirão com os docentes na organização das suas práticas, revestindo-as de intencionalidades e, portanto, como elementos intervenientes no meio social. Nesta perspectiva, conclui-se que a Pedagogia deve oportunizar aos professores os conhecimentos necessários para a construção de práticas que, como desdobramento, façam emergir aprendizagens significativas no contexto escolar. Com isso, teremos professores com uma formação crítica e reflexiva, lhes permitindo contribuir para a consolidação de uma educação pública de qualidade.

\section{REFERENCIAS}

ARAÚJO, Osmar Hélio Alves.; RODRIGUES, Janine Marta Coelho.; ARAGÃO, Wilson Honorato. O (des)lugar da pedagogia e da didática na formação dos professores. 
Revista on line de Política e Gestão Educacional, Araraquara, v.21, n.01, p. 215-226, 2017. Disponível em: <http://dx.doi.org/10.22633/rpge.v21.n.1.2017.9534>. ISSN: 1519-9029.

ARAUUJO, Osmar Hélio.; RIBEIRO, Alves e Luís Távora Furtado. A didática e a pedagogia como suporte teórico para uma coordenação pedagógica qualificada. Revista on line de Política e Gestão Educacional, Araraquara, v.20, n.2, p. 501-513, 2016. Disponível em: <http://dx.doi.org/10.22633/rpge.v20.n3.9533>. ISSN: 1519-9029.

ARAÚJO, Osmar Hélio Alves; MAGALHÃES, Célia de Jesus Silva. A formação docente didático-pedagógica a partir do olhar dos coordenadores pedagógicos. In: ANDRADE, Francisco Ari de; TAHIM, Ana Paula Vasconcelos de Oliveira; CHAVES, Flávio Muniz (org.). Educação, saberes e práticas. Curitiba: CRV, 2016. pp. 223-232.

ARAÚJO, Osmar Hélio Alves; MAGALHÃES, Célia de Jesus Silva. Que raio de coordenador pedagógico sou eu? Tocável? Coordenador fórmula 1. In: ARAÚJO, Osmar Hélio Alves; MAGALHÃES, Célia de Jesus Silva (org.). Do Contexto literário à reflexão sobre a educação na contemporaneidade: a educação em mosaico. Curitiba: CRV, 2017. pp. 175-184.

FRANCO, Maria Amélia do Rosário Santoro. Pedagogia e Prática Docente. 1.ed. São Paulo: Cortez, 2012.

FRANCO, Maria Amélia do Rosário Santoro. Didática: uma esperança para as dificuldades pedagógicas do Ensino superior?Práxis Educacional, Vol. 9, No 15, 2013. Disponível em: < http://periodicos.uesb.br/index.php/praxis/article/view/1947 >.Acesso em: 04 maio 2016.

FRANCO, Maria Amélia do Rosário Santoro. Práticas pedagógicas de ensinaraprender:por entre resistências e resignações. Educ. Pesqui., São Paulo, v. 41, n. 3, p. 601-614, jul./set. 2015. Disponível em: < http://www.scielo.br/pdf/ep/v41n3/15179702-ep-41-3-0601.pdf > . Acesso em: 03 maio 2016.

LIBÂNEO, José Carlos. Democratização da Escola Pública: a pedagogia críticosocial dos conteúdos. São Paulo: Loyola, 2008.

LIBÂNEO, José Carlos. Pedagogia e Pedagogos, Para Quê?. São Paulo: Cortês, 2010.

PIMENTA, Selma Garrido; LIMA, Maria Socorro Lucena. O estágio na formação de professores: unidade teoria e prática? 8. ed - São Paulo: Cortez, 2009.

PEREIRA, Júlio Emilio Diniz. As licenciaturas e as novas políticas educacionais para a formação docente. Educação e Sociedade, Campinas, v. 20, n. 68, 1999.

SAVIANI, Dermeval. Educação: Do Senso Comum à Consciência Filosófica. Campinas, SP: Cortez Editora: Autores Associados, 1991. 
TARDIF, Maurice. LESSARD, Claude. O trabalho docente: elementos para uma teoria da docência como profissão de interações humanas. $3^{\circ}$ ed. - Petrópolis, RJ: vozes, 2007.

NÓVOA, Antônio. O futuro ainda demora muito tempo?, Lisboa: Educa, 2009.

MARQUES, Amanda Cristina Teagno Lopes. PIMENTA, Selma Garrido. É posível formar professores sem os sabres da pedagogia?: Uma reflexão sobre docência e saberes. Revista Metalinguagens, n. 3, mai.2015, p. 135-156. Disponível em: < http://metalinguagens.spo.ifsp.edu.br/wp-content/uploads/2015/05/Amanda-CristinaTeagno-Lopes-MARQUES-e-Selma-Garrido-PIMENTA.pdf >. Acesso em: 03 maio 2016.

\section{Como referenciar este artigo}

MORAES, Cloves Santos de.; LIMA, Cícera Janaína Rodrigues.; MAGALHÃES, Célia de Jesus Silva. A formação inicial dos professores, a pedagogia e a didática em uma perspectiva dialógica. Revista on line de Política e Gestão Educacional, Araraquara, v.12, n.2, p. 563-574, maio/ago. 2017. Disponível em: <http://dx.doi.org/10.22633/rpge.v21.n.2.2017.9740>. ISSN: 1519-9029.

Submetido em: 18/04/2017

Aprovado em: 20/07/2017 